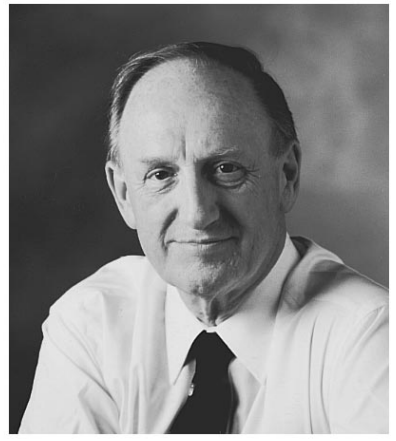

\section{What! Take a Vacation! Who...Me!?}

My family will tell you that extended vacations are not something that I am well known for-quite the contrary. I am not really sure why that is. Perhaps it is because I am usually overcommitted to a variety of projects. Or, of course, it could be that as I grew up, family vacations ceased with the outbreak of World War II and we got out of the habit!

Another view is that like C. S. Lewis, I think that holidays are for children. Lewis wrote in Surprised by Joy: "Terms, holidays, term, holidays, till we leave school, and then work, work, work, till we die."

A counter to Lewis' point of view is that the true scholar has no need for vacation because the pursuit of knowledge is itself so varied and challenging that no rest is needed. As Charles Dickens wrote in Nicholas Nickleby:

At Mr. Wackford Squeers's Academy, Dotheboys Hall, at the delightful village of Dotheboys, near Greta Bridge in Yorkshire, Youth are boarded, clothed, booked, furnished with pocketmoney, provided with all necessaries, instructed in all languages living and dead, mathematics, orthography, geometry, astronomy, trigonometry, the use of the globes, algebra, single stick (if required), writing, arithmetic, fortification, and every other brand of classical literature. Terms, twenty guineas per annum. No extras, no vacations, and diet unparalleled.
Times have changed in my life and I claim to be retired, so surely the normal academic excuses for not taking a vacation no longer apply. But what about Optical Engineering? How can I be away? But reviewers are unable to review papers because they are about to leave on vacation or their assistant writes to me that "Dr. away on vacation and will not return until is thors say that they will not be able to send their revised manuscript to me until early September because they will be away on vacation during August.

By the time you read this, I will have sent myself a memo saying that I will be away on vacation from August 3 through 24 and that my journal office in Rochester will be closed from August 3 to 17. Of course, much of the routine work of the journal will continue; the offices in Bellingham will cover for me since they will be fully operational. All I have to worry about now is catching up when I get back!

\section{Editor's Anecdote}

As many of you know, one of my other activities for the society is as General Editor of the SPIE Milestone Series of Selected Papers. Recently I received a letter about the Milestone Series and the writer made the error of calling it the Millstone Series. There are days when I feel that the writer may have the right title! 